\title{
Development and Validation of the Body Knowledge Questionnaire (Phase 2)
}

\author{
David A. Hernandez \\ Newport Beach, California \\ Cheri Ann Hernandez \\ University of Windsor
}

\begin{abstract}
This study evaluated the psychometric properties of the Body Knowledge Questionnaire (BKQ), an instrument that measures weight management integration: an individual's attitudes, preferences, and behaviors associated with weight self-management. The BKQ was revised following a pilot study demonstrating its validity and reliability, and new items were added based on data gathered through four focus groups of obese and normal-weight survey completers. Additional items were derived from the extant literature on weight management and integration. A panel of 30 health professionals who work in the area of weight management, bariatrics, and nutrition science reviewed the revised BKQ for content validity. Two hundred sixty-seven participants, recruited through Walden University's online participant pool, completed the revised 66-item BKQ through SurveyMonkey. Exploratory factor analysis yielded a five-factor solution (Emotional Eating, Health-Conscious Lifestyle, Conscientious Eating Habits, Food Centricity, and Psychosomatic Awareness), with factor loadings $>$.40. Discriminant function analysis determined that the BKQ full scale and subscales could predict the classification of participants into normal-weight and obese groups for the total sample with $71 \%$ and $79 \%$ accuracy, respectively. Test-retest reliability was .86 , and internal consistency of the overall BKQ was .92. The BKQ instrument has potential for use in individual or group weight management programs and program evaluation; for use in weight management practice areas such as dietetics, diabetes education, nursing, and psychology; or in the development of new weight management interventions.
\end{abstract}

Keywords: obesity, weight management integration, instrument development, Body Knowledge Questionnaire

\section{Introduction}

In the United States in 2014, approximately $35 \%$ of men and $40 \%$ of women were obese (Flegal, Kruszon-Moran, Carroll, Fryar, \& Ogden, 2016). An individual whose body mass index (BMI) is $\geq 30$ $\mathrm{kg} / \mathrm{m}^{2}$ is considered obese. Obesity is a chronic disease that has become a major health problem of epidemic proportion in the United States (Alpert, 2009; Bhupathiraju \& Hu, 2016), especially because obesity is linked to heart disease (Breuhl Smith \& Smith, 2016), the leading cause of death in the United States in 2010 (Heron, 2013). Moreover, researchers have linked obesity to other physiological disorders such as cancer, diabetes mellitus, osteoarthritis, hypertension, and stroke (Breuhl Smith \& Smith, 2016) and psychosocial consequences such as depression, prejudice, and low

This research was supported by a Faculty Research Initiative Grant from Walden University, Minneapolis, Minnesota. The authors declare no conflict of interest.

Please address queries to: David A. Hernandez, 18261\%2 West Balboa Boulevard, Newport Beach, CA 92663. Email: dahernan@earthlink.net 
self-esteem (Sutton \& Raines, 2010) that lead to life-threatening or chronic conditions (Egger \& Dixon, 2014). However, weight loss programs that seek to restrict calorie intake and increase energy expenditure have yielded poor results, with only short-term success; that is, within 6 years, individuals return to or exceed their preweight-loss-program BMI (Kraschnewski et al., 2010; Mekary, Feskanich, Hu, Willett, \& Field, 2010). Recent literature has reported much poorer outcomes in terms of long-term post-intervention weight loss maintenance (i.e., $\leq 2$ years; Gilmartin \& Murphy, 2015).

Some researchers have identified the process of integration of self and one's weight as an important aspect in weight management (Johnson, 1990; White, 1984). During the process of integration, obese individuals struggle to reconcile two selves, their actual, obese-weight self with a desired, normalweight self. Once integration has occurred, individuals think and act differently, adopting a "new [healthier] way of eating and living" (Johnson, 1990, p. 1294). Currently, there is a paucity of research that has studied the experiential aspects (i.e., psychological, behavioral, and social experiences) of an individual's weight self-management (e.g., finding comfort in food, eating everything on one's plate, reaction of others to self; D. A. Hernandez \& Hernandez, 2015), which could be used to more fully understand the integration process.

In 2009, a pilot study was conducted to investigate whether the theory of integration (explained here under Theoretical Framework) could be applied in the domain of weight self-management (D. A. Hernandez \& Hernandez, 2015). In this pilot study, the psychometric properties of a new instrument, the Body Knowledge Questionnaire (BKQ), designed to measure integration (i.e., an individual's attitudes, preferences, and behaviors) related to weight self-management, were evaluated. Items on the BKQ were derived from two sources-a preliminary review of the obesity/weight management literature and The Diabetes Questionnaire (C. A. Hernandez, 1997). Once the validity and reliability of the initial $\mathrm{BKQ}$ were established, the researchers undertook a second phase of the research to ensure that the BKQ contained items from the total domain of weight management integration, which resulted in new items being added to the questionnaire.

The BKQ gathers data about an individual's attitudes (thoughts and feelings), preferences (choices), and behaviors (actions) related to weight self-management. Information about the attitudes, preferences, and behaviors characteristic of individuals' weight management efforts is important because that knowledge can be used to create innovative weight management intervention programs and strategies based on the attitudes, preferences, and behaviors more characteristic of healthier, normal-weight individuals. Consequently, the purpose of this research was to refine and validate the $\mathrm{BKQ}$, an instrument which measures the ways (attitudes, preferences, and behaviors) in which individuals internalize and manage their weight.

\section{Theoretical Framework}

The theory used to frame this study was C. A. Hernandez's (1991) theory of integration. This theory explains the process of integration that occurs in individuals with diabetes. Individuals endeavor to assimilate the existence of two selves: a personal self, which has always existed, and a diabetic self, which emerged when diagnosed with diabetes. Besides explaining the experiences of individuals with Type 1 (C. A. Hernandez, 1991) and Type 2 diabetes (C. A. Hernandez, 1997), the theory of integration has been used in other chronic illnesses as well, such as Crohn's disease (Compton, 2002) and chronic pain (Deshaies \& Hernandez, 2011). Hernandez's theory of integration has not been applied to the field of weight management, but the authors posited it would be a useful framework 
because previous qualitative studies have indicated that integration is an important part of the experience of those who are seeking to lose weight (Johnson, 1990; White, 1984).

\section{Method}

The BKQ is a self-report instrument for collecting data on an individual's attitudes (thoughts and feelings), preferences (choices), and behaviors (actions) as they relate to managing one's weight. The process used to develop and validate the BKQ is displayed in Figure 1. There were two phases to this research project.

\section{Instrument Development (Phase 1)}

In Phase 1, the conceptual model was defined. The initial version of the BKQ was created by using items focused on the concept of integration from the The Diabetes Questionnaire (C. A. Hernandez, 1997) and then revising the wording to align with the weight management paradigm.

Additional items were created from the findings of the extant research literature on weight management. For example, the results of one study revealed that individuals were more successful at weight maintenance when they weighed themselves once a day or more (Butryn, Phelan, Hill, \& Wing, 2007). This finding was converted into Item 26 on the initial BQK: "I weigh myself daily to monitor my weight." Forty participants completed the initial BKQ instrument in a pilot study. With analysis of the data from the pilot study, the authors showed the scale and subscales of the BKQ were both reliable and valid (D. A. Hernandez \& Hernandez, 2015). With solid initial indicators of the capacity of the BKQ in identifying the attitudes, behaviors, and preferences of those successful (and unsuccessful) in maintaining normal body weight, the authors continued with Phase 2 of the research, which was the refinement of the BKQ instrument and evaluation of the psychometric properties of the revised instrument.

\section{Continued Instrument Development (Phase 2)}

Besides completing the initial draft of the BKQ, during Phase 1, the respondents participated in one of four focus group interviews. The focus group sessions were audiotaped and transcribed verbatim, and in Phase 2 of this research, the transcripts were analyzed for new attitudes, preferences, and behaviors related to weight management that had not already been included in the first version of the 27-item BKQ. An additional 22 new items were added to the BKQ based on the content in the focus group transcripts.

The subsequent step was to conduct a comprehensive search of the literature to identify any additional attitudes, preferences, or behaviors related to weight management in the extant research literature. Seven databases (PsycINFO, PubMed, Scopus, CINAHL, Cochrane Collaboration, Web of Science, and National Weight Control Registry) were searched, and approximately 2,000 articles about weight, weight loss/control, and eating behaviors from 2008 to 2014 were identified and reviewed. The outcome was the identification of an additional 10 new items for the BKQ. 


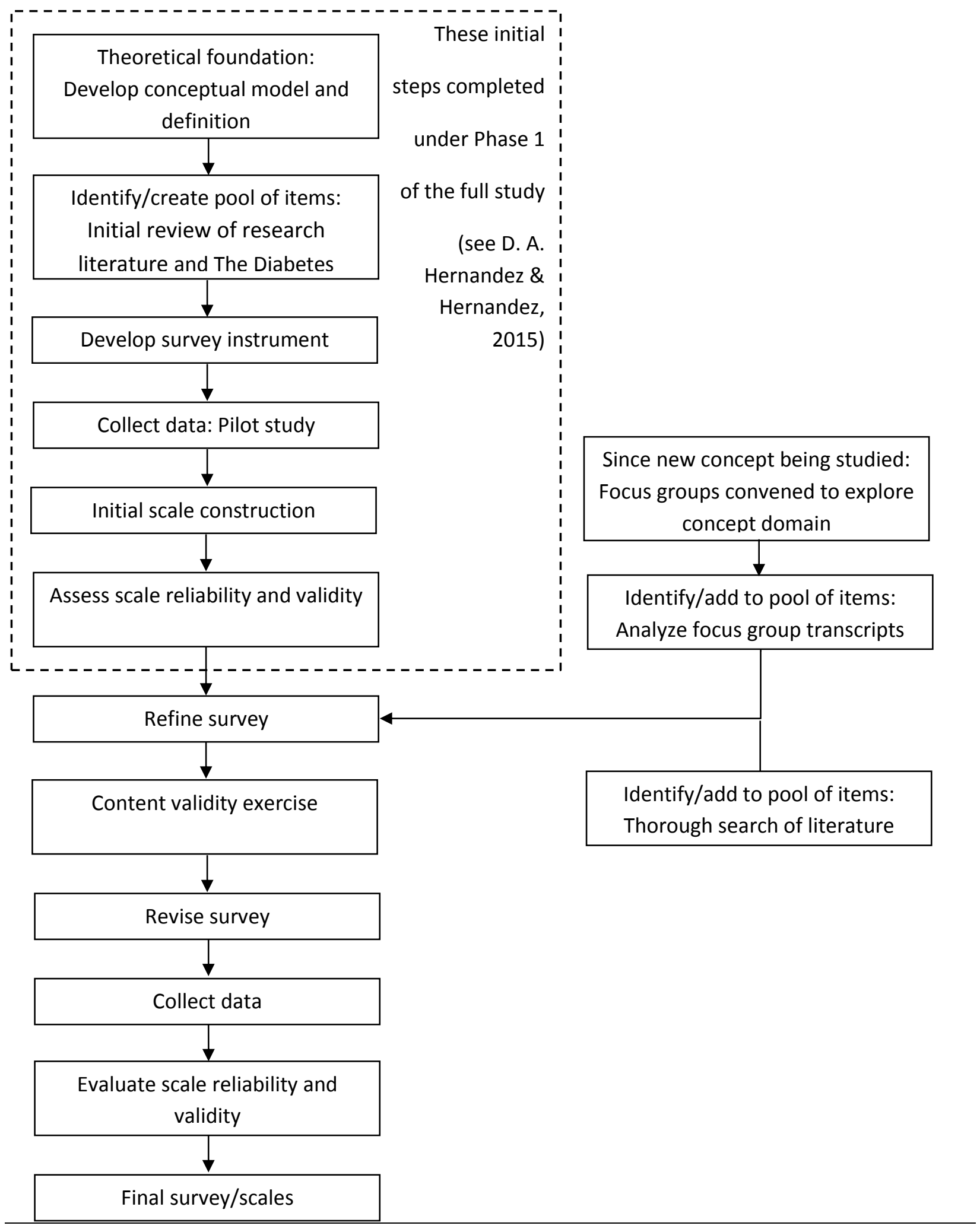

Figure 1. Process of development of the Body Knowledge Questionnaire. 
The content of the revised 59-item BKQ was reviewed by a panel of 30 health professionals (14 dietitians, eight nurse/nurse practitioners, two psychologists/psychotherapists, two social workers, one physiotherapist, one respiratory therapist, one human kinetics professional, and one health promoter) who work in the area of weight management, bariatrics, and nutrition science. Each participant completed a five-item Content Validity Questionnaire (see Appendix). Subsequently, a subgroup of six of the 30 health professionals who completed the Content Validity Questionnaire participated in a focus group exercise to review the results of the Content Validity Questionnaire and provide feedback. An additional seven new items were added, and the wording of existing items were revised. The final BKQ consisted of 66 items.

\section{Sample}

Participants were recruited through Walden University's Research Participant Pool. Once the current study was approved by Walden University's Institutional Review Board (Approval Number 03-03-14-0437626), access was granted to its Research Participant Pool. An e-mail was generated by the Research Participant Pool administrator and sent to Walden's currently enrolled students informing them of the study and inviting them to participate in the research by completing the online questionnaire. Because the Research Participant Pool administrator does not track the number of enrolled students who received the e-mail inviting them to participate in this study, a response rate for the $\mathrm{BKQ}$ could not be calculated.

The first webpage of the questionnaire provided participants with information about the background, purpose, risks and benefits, and voluntary nature of their participation. No compensation was given to participants for completing the BKQ. Individuals were excluded from the study if, on average, they drank more than one alcoholic beverage/day for women or more than two alcoholic beverages/day for men; smoked tobacco; were a substance abuser; were pregnant; had an eating disorder, diabetes, chronic obstructive pulmonary disease, gastrointestinal problems, or serious psychiatric illness; took psychiatric medication or medication for a thyroid condition; or were being treated for kidney disease. These exclusionary criteria are factors known to impact weight management.

To identify differences in the attitudes, preferences, and behaviors between normal-weight and obese individuals, both normal-weight and obese participants were included in the sample. Individuals who were categorized as simply overweight (i.e., BMI > 24.9 and < 30.0) were excluded from the study. The first webpage of the online version of the BKQ included two tables, one using U.S. standard units and one using metric units, which identified for potential participants whether they were eligible to complete the survey. The tables, sorted by increasing height, included the acceptable weight ranges for participants at each height. To ensure that only normal-weight and obese individuals were included in the final analysis, respondents self-reported their weight and height as part of the data collection, and those values were used to calculate an exact BMI.

Two hundred sixty-seven participants completed the survey through SurveyMonkey, of which 236 were female and 31 were male. One hundred seventy-five participants $(65.5 \%)$ were of normal weight and $92(34.5 \%)$ were obese. Table 1 provides a profile of the participants on select demographic variables. 


\section{Overview of psychometric evaluation}

There are two important psychometric properties of an instrument: validity and reliability. Validity is a measure of the degree to which an instrument measures accurately the underlying construct it is purported to measure, and reliability measures if the instrument does so consistently (LoBiondoWood \& Haber, 2014).

Table 1. Demographic Data for Study Participants

\begin{tabular}{|c|c|c|}
\hline Demographic & Frequency & Percentage \\
\hline \multicolumn{3}{|l|}{ Gender } \\
\hline Female & 236 & 88.4 \\
\hline Male & 31 & 11.6 \\
\hline \multicolumn{3}{|l|}{ Marital status } \\
\hline Single, never married & 113 & 42.3 \\
\hline Married, common law & 112 & 41.9 \\
\hline Separated & 4 & 1.5 \\
\hline Remarried & 8 & 3.0 \\
\hline Divorced & 24 & 9.0 \\
\hline Widowed & 6 & 2.2 \\
\hline \multicolumn{3}{|l|}{$\begin{array}{l}\text { Highest education level } \\
\text { achieved }\end{array}$} \\
\hline High school graduate & 17 & 6.4 \\
\hline College diploma & 18 & 6.7 \\
\hline Bachelor's degree & 82 & 30.7 \\
\hline Master's degree & 130 & 48.7 \\
\hline Doctoral degree & 20 & 7.5 \\
\hline \multicolumn{3}{|l|}{ Ethnicity } \\
\hline African American/Black & 32 & 12.0 \\
\hline Asian or Pacific Islander & 33 & 12.4 \\
\hline First Nations/Native & 2 & 0.7 \\
\hline \multicolumn{3}{|l|}{ American } \\
\hline Hispanic/Latino/Spanish & 20 & 7.5 \\
\hline Middle Eastern & 7 & 2.6 \\
\hline White/European descent & 171 & 64.0 \\
\hline No response & 2 & 0.7 \\
\hline \multicolumn{3}{|l|}{ Annual household income } \\
\hline$\leq \$ 10,000$ & 26 & 9.7 \\
\hline$\$ 10,001-\$ 20,000$ & 22 & 8.2 \\
\hline$\$ 20,001-\$ 30,000$ & 14 & 5.2 \\
\hline$\$ 30,001-\$ 40,000$ & 20 & 7.5 \\
\hline$\$ 40,001-\$ 50,000$ & 21 & 7.9 \\
\hline$\$ 50,001-\$ 60,000$ & 24 & 9.0 \\
\hline$\$ 60,001-\$ 70,000$ & 11 & 4.1 \\
\hline$\$ 70,001-\$ 80,000$ & 16 & 6.0 \\
\hline$\$ 80,001-\$ 90,000$ & 24 & 9.0 \\
\hline$\$ 90,001-\$ 100,000$ & 16 & 6.0 \\
\hline$\$ 100,001-\$ 110,000$ & 12 & 4.5 \\
\hline$>\$ 110,000$ & 53 & 19.9 \\
\hline No response & 8 & 3.0 \\
\hline
\end{tabular}


Using psychometrically sound instruments (i.e., instruments with adequate validity and reliability) ensures the integrity and trustworthiness of the research (LoBiondo-Wood \& Haber, 2014), and without them, interpretations of the research can be neither justifiable nor meaningful (DeVellis, 2017). Traditionally, an instrument's validity is measured by three types: (a) content validity, (b) construct validity, and (c) criterion-related validity (LoBiondo-Wood \& Haber, 2014), and these were established for the BKQ in this research. The BKQ's reliability was established using test-retest reliability to assess its temporal stability, and through scale reliability analysis to establish the internal consistency on the items of the constructs measured.

\section{Instrument Validity}

To determine the validity of an instrument, LoBiondo-Wood and Haber (2014) advocated establishing various types of validity. For the BKQ, content, construct (including convergent validity), and criterion-related validity were confirmed in this research.

\section{Content validity}

The content of the BKQ was derived from four sources: (a) The Diabetes Questionnaire, (b) the research literature on weight management, (c) transcripts of focus group interviews of obese and normal-weight individuals, and (d) a panel of experts, who work in weight management, bariatrics, and nutrition science. Establishing the content validity of an instrument is an essential prerequisite prior to using it for research or assessment because it impacts the inferences one can make about the data collected (Peirce, Brown, Corkish, Lane, \& Wilson, 2016). Content validity refers to the degree of relevance and representatives of an instrument to the targeted construct (DeVellis, 2017). This means that each item of the $\mathrm{BKQ}$ should measure aspects of weight management integration. When studying new constructs, Patrick et al. (2011) recommended interviewing a sample of individuals from the target population to identify the relevant facets of the construct from which questionnaire items can be formulated. Four focus group interviews were conducted with 40 participants (both normal-weight and obese individuals), and from the focus group transcripts, 22 new items were derived.

Prior to conducting other types of validation of the BKQ, 30 health professionals reviewed the BKQ and completed the Content Validity Questionnaire. A subgroup of six of the 30 health professionals participated in a focus group for the final content validity exercise. This "panel of experts" was used to establish the content validity of the final version of the BKQ, which became a 66 -item instrument.

\section{Construct and convergent validity}

To determine an instrument's construct validity, LoBiondo-Wood and Haber (2014) recommended using multiple methods, which reduces the impact of measurement (systematic) error-a potential threat to research findings. One statistical method for assessing construct validity is exploratory factor analysis (EFA), which identifies latent constructs (or factors) that explain the covariance among the survey items or individual variables in a data set (Tabachnick \& Fidell, 2012).

A second method of assessing construct validity is to measure the degree to which two attempts to measure the same concept are in agreement (LoBiondo-Wood \& Haber, 2014). This is known as convergent validity. To establish convergent validity, bivariate correlations $(r s)$ were calculated to measure the association between the BKQ and Impact of Weight on Quality of Life Questionnaire (IWQOL)-Lite scales and subscales. The IWQOL-Lite is a psychometrically sound self-report instrument that measures the effect of obesity on quality of life (Kolotkin, Crosby, Kosloski, \& Williams, 2001). A lower score on the BKQ (indicating poorer weight self-management) should be 
correlated to a higher score on the IWQOL-Lite (indicating poorer quality of life due to obesity). An $|r|$ value of .21 to .40 suggests a moderate/acceptable degree of correlation, an $|r|$ value of .40 to .50 suggests a high correlation, and an $|r|>.50$ suggests a very high correlation, and the threshold to establish convergent validity is a moderate degree of correlation between two measures (Drummond, Sheperis, \& Jones, 2016). In the current research, the BKQ's construct validity was established using EFA and its convergent validity was established using correlation analysis.

However, prior to any statistical analysis, 35 questions had to be reverse coded so all items with higher agreement scores would indicate better weight management integration (e.g., Items 2, 4, 5, 8, $9,12,14,17,18,20,25,26,29,32,33,34,36,37,38,39,40,42,44,46,47,48,50,51,55,57,60,61$, 62,65 , and 66 were reverse coded). After EFA, items with factor loadings $<.40$, the factor loading cut score recommended by Stevens (2009) were excluded from further analysis. Additionally, the BKQ scale and subscale values were calculated using the averaging method. In the averaging method, the factor score is calculated as the mean of the items comprising the factor. This method facilitates "comparisons across factors when there are differing numbers of items per factor" (DiStefano, Zhu, \& Mîndrilă, 2009, p. 2).

\section{Criterion-related validity}

One type of criterion-related validity is predictive validity (DeVellis, 2017); in other words, how well does the BKQ predict the construct it purports to measure. Discriminant function analysis (DFA) is used for prediction (i.e., predictive discriminant analysis) and can be used to determine the components on which groups differ (e.g., weight categories; Mertler \& Vannatta, 2017). DFA was used to test whether the BKQ scale and its subscales could accurately classify participants into normal-weight and obese groups.

When assessing criterion-related validity, DeVellis (2017) recommended calculating the percentage of correctly categorized participants referred to as the "hit rate." There is no acceptable rule-ofthumb hit rate. A high hit rate, however, is desirable and indicative of criterion-related validity (Mertler \& Vannatta, 2017).

\section{Instrument Reliability}

Two measures of reliability were calculated. Correlation analysis was used to establish test-retest reliability, which provides an indicator of the stability of the instrument. For adequate temporal stability of an instrument, Drummond et al. (2016) suggested a minimum correlation of .70 or better. Cronbach's alpha scores were calculated to determine the internal consistency of the BKQ's scale and subscales. Cronbach's alpha scores between .70 and .79 are considered adequate, .80 and .89 are considered good, and .90 and above are considered excellent (George \& Mallery, 2016).

\section{Summary of Statistical Analyses}

Using SPSS software, several statistical analyses were undertaken to establish the psychometric properties of the BKQ. EFA was used to establish construct validity. Correlation analysis was used to establish convergent validity and test-retest reliability. DFA was used to establish criterionrelated validity. Finally, Cronbach's alphas were calculated to establish the internal consistency of the BKQ scale and subscales. 


\section{Results}

Prior to conducting EFA, a bivariate correlation matrix was generated to test the correlation among the 66 individual BKQ items. A visual inspection of the correlation matrix revealed that 20 items (Items 1, 6, 12, 13, 19, 21, 23, 35, 41, 43, 45, 46, 51, 52, 53, 54, 58, 59, 63, and 64) lacked a patterned relationship with the other questionnaire items (i.e., a large number [e.g., $>90 \%$ ] of $|r|$ values <.30; Field, 2013; Yong \& Pearce, 2013). Those 20 items were removed, therefore, prior to further analysis.

\section{Exploratory Factor Analysis}

An initial EFA was run to produce a scree plot. Cattell (1966) argued that the number of factors to extract should be at the point of inflexion of the scree plot curve. With the current dataset, the curve descends sharply and then trails off at Component 5 . Therefore, a five-factor solution is indicated.

\section{Five-factor solution}

A second EFA was conducted using a five-factor solution and varimax rotation with Kaiser normalization. A factor loading of .40 was used as the factor loading cut score. Of the 46 questionnaire items, 40 items loaded onto five factors with a factor loading greater than or equal to .40. Twelve items loaded onto Factor 1, eight items onto Factor 2, six items onto Factor 3, seven items onto Factor 4, and seven items onto Factor 5. Items with a factor loading below the cut score were discarded. In the final scale and subscales, BKQ Items 2, 3, 4, 5, 8, 9, 10, 14, 15, 16, 17, 20, 22 , $24,25,26,27,28,29,30,31,32,33,34,36,37,38,39,40,47,48,50,55,56,57,60,61,62$, 65, and 66 were retained. This five-factor solution model explained $48.3 \%$ of the total variance in the data. The rotated component matrix is displayed in Table 2, and the factors, items, and component loadings are displayed in Table 3.

The first factor, composed of 12 items, was named Emotional Eating. Items for this factor indicate that the individual eats when feeling stressed or nervous (Item 8), bored or lonely (Item 25), tired (Item 32), angry or upset (Item 33), or sad or depressed (Item 55). Food is used as a reward (Item 50) or to comfort the individual (Item 57). The individual's eating patterns are affected by emotions. This factor explained the largest single portion (12.8\%) of the variance in the data.

The second factor, composed of eight items, was named Health-Conscious Lifestyle. The individual who scores high on this factor eats lots of vegetable and fruits (Item 10), rarely eats fast food/junk food (Item 30), and does not mostly eat food that comes already prepared (Item 66). Moreover, the individual who scores high on this factor decides how much to eat before the meal and sticks to that amount (Item 24), and limits the portion size of a meal or snack (Item 31). Finally, the individual enjoys exercising regularly (Item 28) and engages in moderate or vigorous physical activity at least five times per week (Item 56). Eating the right foods, avoiding the wrong foods, controlling calorie intake, and exercising regularly are the hallmarks of this factor. 
Table 2. Rotated Component Matrix

\begin{tabular}{|c|c|c|c|c|c|}
\hline \multirow[b]{2}{*}{ Item Number } & \multicolumn{5}{|c|}{ Component } \\
\hline & Factor 1 & Factor 2 & Factor 3 & Factor 4 & Factor 5 \\
\hline $2 \mathrm{R}$ & & & & .601 & \\
\hline 3 & & & & & .459 \\
\hline $4 \mathrm{R}$ & & & .796 & & \\
\hline $5 \mathrm{R}$ & & & & .539 & \\
\hline $8 \mathrm{R}$ & .773 & & & & \\
\hline 9R & & & .612 & & \\
\hline 10 & & .725 & & & \\
\hline $14 \mathrm{R}$ & & & & .620 & \\
\hline 15 & & & .754 & & \\
\hline 16 & & & & & .437 \\
\hline $17 \mathrm{R}$ & .432 & & & & \\
\hline $20 \mathrm{R}$ & & & .780 & & \\
\hline 22 & & & & & .408 \\
\hline 24 & & .595 & & & \\
\hline $25 \mathrm{R}$ & .645 & & & & \\
\hline $26 \mathrm{R}$ & & & & & .522 \\
\hline 27 & & & .562 & & \\
\hline 28 & & .599 & & & \\
\hline $29 \mathrm{R}$ & & & & .643 & \\
\hline 30 & & .727 & & & \\
\hline 31 & & .665 & & & \\
\hline $32 \mathrm{R}$ & .570 & & & & \\
\hline $33 \mathrm{R}$ & .778 & & & & \\
\hline $34 \mathrm{R}$ & & & & .572 & \\
\hline $36 \mathrm{R}$ & .455 & & & & \\
\hline $37 \mathrm{R}$ & .462 & & & & \\
\hline $38 \mathrm{R}$ & & & & & .716 \\
\hline $39 \mathrm{R}$ & & & & .590 & \\
\hline $40 \mathrm{R}$ & & & & .567 & \\
\hline $47 \mathrm{R}$ & & & .497 & & \\
\hline $48 \mathrm{R}$ & .427 & & & & \\
\hline $50 \mathrm{R}$ & .574 & & & & \\
\hline $55 \mathrm{R}$ & .807 & & & & \\
\hline 56 & & .569 & & & \\
\hline $57 \mathrm{R}$ & .644 & & & & \\
\hline $60 \mathrm{R}$ & & & & & .491 \\
\hline $61 \mathrm{R}$ & .440 & & & & \\
\hline $62 \mathrm{R}$ & & & & & .505 \\
\hline $65 \mathrm{R}$ & & .550 & & & \\
\hline $66 \mathrm{R}$ & & .606 & & & \\
\hline Eigenvalues & 5.898 & 4.708 & 4.177 & 3.993 & 3.459 \\
\hline$\%$ variance explained & 12.821 & 10.236 & 9.080 & 8.681 & 7.519 \\
\hline
\end{tabular}


Table 3. Factors, Survey Items of the Body Knowledge Questionnaire, ${ }^{a}$ and Component Loadings

\begin{tabular}{|c|c|c|}
\hline Item & Description & $\begin{array}{l}\text { Component } \\
\text { Loading }\end{array}$ \\
\hline \multicolumn{3}{|c|}{ Factor 1 (Emotional Eating) } \\
\hline $8^{\mathrm{b}}$ & I eat when I feel stressed or nervous. & .773 \\
\hline $17^{\mathrm{b}}$ & I give in when I crave sweets/snack foods. & .432 \\
\hline $25^{\mathrm{b}}$ & I eat when I am bored or lonely. & .645 \\
\hline $32^{\mathrm{b}}$ & I eat/drink more when I am tired. & .570 \\
\hline $33^{\mathrm{b}}$ & I eat when I am angry or upset. & .778 \\
\hline $36^{\mathrm{b}}$ & I overeat because I am often eating on the run. & .455 \\
\hline $37^{\mathrm{b}}$ & Occasionally, I am a binge eater. & .462 \\
\hline $48^{\mathrm{b}}$ & If my meal is significantly delayed, I will overeat. & .427 \\
\hline $50^{\mathrm{b}}$ & I often use food to reward myself. & .574 \\
\hline $55^{\mathrm{b}}$ & I eat when I am sad or feel depressed. & .807 \\
\hline $57^{\mathrm{b}}$ & I find food comforts me. & .644 \\
\hline $61^{\mathrm{b}}$ & When I skip a meal, I eat more than usual at the next meal. & .440 \\
\hline \multicolumn{3}{|c|}{ Factor 2 (Health-Conscious Lifestyle) } \\
\hline 10 & My body is used to healthy foods-lots of vegetables and fruits. & .725 \\
\hline 24 & Before a meal, I decide how much I will eat and then stick to that. & .595 \\
\hline 28 & I exercise regularly because I enjoy it. & .599 \\
\hline 30 & I rarely eat fast food/junk food. & .727 \\
\hline 31 & I automatically limit the portion size of my meal or snack. & .665 \\
\hline 56 & $\begin{array}{l}\text { On at least } 5 \text { days/week, I engage in moderate or vigorous physical activity } \\
\text { that makes me sweat. }\end{array}$ & .569 \\
\hline $65^{\mathrm{b}}$ & I eat out more than three times a week. & .550 \\
\hline $66^{\mathrm{b}}$ & I mostly eat foods that come already prepared in boxes, cans, or plastic bags. & .606 \\
\hline \multicolumn{3}{|c|}{ Factor 3 (Conscientious Eating Habits) } \\
\hline $4^{\mathrm{b}}$ & I finish the food on my plate when I eat out. & .796 \\
\hline $9^{b}$ & I feel guilty if I don't eat all the food on my plate. & .612 \\
\hline 15 & I rarely eat all the food on my plate. & .754 \\
\hline $20^{\mathrm{b}}$ & I always eat everything on my plate. & .780 \\
\hline 27 & $\begin{array}{l}\text { When I eat appetizers or snack just before a meal, I tend to eat less at the } \\
\text { meal. }\end{array}$ & .562 \\
\hline $47^{\mathrm{b}}$ & Once I open a package (bag, box, etc.), I have to eat until it is empty. & .497 \\
\hline \multicolumn{3}{|c|}{ Factor 4 (Food Centricity) } \\
\hline $2^{\mathrm{b}}$ & I prefer to plan social events or time with friends around a meal. & .601 \\
\hline $5^{\mathrm{b}}$ & I plan my day around meal times. & .539 \\
\hline $14^{\mathrm{b}}$ & I live to eat. & .620 \\
\hline $29^{b}$ & Food is a major focus of my life. & .643 \\
\hline $34^{\mathrm{b}}$ & Seeing food or food ads cues me to eat. & .572 \\
\hline $39^{\mathrm{b}}$ & I think about food all the time. & .590 \\
\hline $40^{\mathrm{b}}$ & If I smell food, I eat. & .567 \\
\hline \multicolumn{3}{|c|}{ Factor 5 (Psychosomatic Awareness) } \\
\hline 3 & I pay attention to cues from my body that tell me when to eat. & .459 \\
\hline 16 & Maintaining a normal weight is natural for me. & .437 \\
\hline 39 & I pay attention to cues from my body that tell me to stop eating. & .408 \\
\hline $26^{\mathrm{b}}$ & I weigh and record my weight one or more times a week to monitor my weight. & .522 \\
\hline $38^{\mathrm{b}}$ & I focus on my weight constantly. & .716 \\
\hline $60^{\mathrm{b}}$ & I eat more when others make negative comments about my weight. & .491 \\
\hline $62^{\mathrm{b}}$ & Food helps me deal with the pain from childhood abuse/trauma. & .505 \\
\hline
\end{tabular}

${ }^{a}$ Reprinted with permission. Copyright 2015, Authors. ${ }^{b}$ Reverse-coded item. 
The third factor, composed of six items, was named Conscientious Eating Habits because items in the third factor relate to the individual's making good choices about food consumption. Items that were reverse coded indicate an individual disagrees that he or she always eats everything on his or her plate (Item 20) or feels guilty if not all the food on one's plate is eaten (Item 9), and once a food package is opened, he or she does not eat until the package is empty (Item 47). Furthermore, an individual who scores high on this factor rarely eats all the food on his or her plate (Item 15) and eats less at a meal if appetizers or snacks are consumed before the meal (Item 27). An individual scoring high on this factor makes a conscious choice of how much he or she should and will eat.

The fourth factor, composed of seven items, was named Food Centricity because the items in this factor indicate that food is central to the individual's thinking. For example, this factor includes items like "I live to eat" (Item 14), "food is a major focus of my life" (Item 29), and "I think about food all the time" (Item 39). Because the individual plans the day around meal times (Item 5) and prefers to plan social events or time with friends around a meal (Item 2), this suggests the great importance food plays in the individual's life.

The fifth factor, composed of seven items, was named Psychosomatic Awareness because items in this last factor relate to the individual's tuning in to his or her body's need for food. For example, the individual pays attention to cues from the body to signal when to eat (Item 3) and when to stop eating (Item 22), and maintaining a normal weight is natural (Item 16). Reverse-coded items indicate the individual does not need to focus constantly on one's weight (Item 38) or weigh oneself weekly to maintain a constant weight (Item 26), presumably because the individual is in tune with his or her body. In other words, the individual has a natural sense of whether his or her weight is within the normal range without having to weigh oneself or focusing on one's weight.

\section{Sampling adequacy and adequacy of correlation matrix}

The Kaiser-Meyer-Olkin measure of sampling adequacy was .90, indicating that the sample size of this research was "marvelous" (Kaiser, 1974, p. 36) or has excellent acceptability for the factor analysis. Bartlett's test of sphericity was significant, $\chi^{2}(1,035)=5,626.74, p<.001$. A significant Bartlett's test indicates that there are relationships among the variables. Therefore, interpretation of a factor analysis is appropriate.

\section{Correlation Analysis}

The results of bivariate correlation analysis measuring the association between the BKQ and IWQOL-Lite scale and subscales are displayed in Table 4. All correlations between the two instruments are negative and are between -.06 (nonsignificant) and -.61 (significant). The Pearson $r$ s between the full BKQ scale and subscales and the IWQOL-Lite full scale and subscales provide evidence of convergent validity. Additionally, four of the five BKQ subscales (Emotional Eating, Health-Conscious Lifestyle, Conscientious Eating Habits, and Psychosomatic Awareness) demonstrated convergent validity with the IWQOL-Lite full scale and at least two or more of the subscales. The fifth BKQ subscale, Food Centricity, demonstrated convergent validity with two of the IWQOL-Lite subscales. A total of 28 moderate-to-very-high correlations between the BKQ and IWQOL-Lite scales and subscales established convergent validity and are shown in bold on Table 4. 
Table 4. Pearson Correlation Coefficients Between the Body Knowledge Questionnaire (BKQ) and Impact of Weight on Quality of Life (IWQOL)-Lite Scale and Subscales

\begin{tabular}{|c|c|c|c|c|c|c|}
\hline \multirow[b]{2}{*}{ Variable } & \multicolumn{6}{|c|}{ IWQOL-Lite } \\
\hline & $\begin{array}{c}\text { Full } \\
\text { Scale }\end{array}$ & Physical & $\begin{array}{c}\text { Self- } \\
\text { Esteem }\end{array}$ & $\begin{array}{c}\text { Sexual } \\
\text { Life }\end{array}$ & $\begin{array}{c}\text { Public } \\
\text { Distress }\end{array}$ & Work \\
\hline BKQ full scale & $-.53^{* *}$ & $-.38^{* * *}$ & $-.59^{* *}$ & $-.44^{* *}$ & $-.34^{* *}$ & $-.34^{* *}$ \\
\hline $\begin{array}{l}\text { Emotional } \\
\text { Eating } \\
\text { subscale }\end{array}$ & $-.45^{* *}$ & $-.29^{* *}$ & $-.55^{* *}$ & $-.39^{* *}$ & $-.28^{* *}$ & $-.29^{* * *}$ \\
\hline $\begin{array}{l}\text { Health- } \\
\text { Conscious } \\
\text { Lifestyle } \\
\text { subscale }\end{array}$ & $-.43^{* *}$ & $-.37^{* *}$ & $-.43^{* *}$ & $-.30^{* *}$ & $-.29^{* *}$ & $-.31^{* * *}$ \\
\hline $\begin{array}{l}\text { Conscientious } \\
\text { Eating } \\
\text { Habits } \\
\text { subscale }\end{array}$ & $-.25^{* *}$ & $-.20^{* *}$ & $-.27^{* * *}$ & $-.20^{*}$ & $-.13^{*}$ & $-.20^{* *}$ \\
\hline $\begin{array}{l}\text { Food } \\
\text { Centricity } \\
\text { subscale }\end{array}$ & $-.20^{* *}$ & -.10 & $-.27^{* *}$ & $-.23^{* * *}$ & -.11 & -.06 \\
\hline $\begin{array}{l}\text { Psychosomatic } \\
\text { Awareness } \\
\text { subscale }\end{array}$ & $-.58^{* *}$ & $-.43^{* * *}$ & $-.61^{* *}$ & $-.47^{* *}$ & $-.41^{* * *}$ & $-.38^{* *}$ \\
\hline
\end{tabular}

Note. Boldface indicates support for convergent validity.

${ }^{*} p<.01 . * * p<.001$.

Correlational analysis was also used to establish test-retest reliability. Twenty-four participants completed the BQK twice, with a median and modal value of 8 days between the first and second completion dates. The response values of 40 items comprising the full BKQ scale were summed, and the bivariate correlation of the total item scores between initial and second completion of the BKQ yielded a Pearson $r$ of .86, $p<.001$. The BKQ demonstrates adequate test-retest reliability.

\section{Cronbach's Alpha}

Results of the reliability analysis for each of the five factors were as follows: Factor 1 with 12 items (questionnaire Items $8,17,25,32,33,36,37,48,50,55,57$, and 61 ) yielded a Cronbach's alpha value of .89, Factor 2 with eight items (questionnaire Items 10, 24, 28, 30, 31, 56, 65, and 66) yielded a Cronbach's alpha of .82, Factor 3 with six items (questionnaire Items 4, 9, 15, 20, 27, and 47) yielded a Cronbach's alpha of .83, Factor 4 with seven items (questionnaire Items 2, 5, 14, 29, 34, 39, and 40) yielded a Cronbach's alpha of .85, and finally, Factor 5 with seven items (questionnaire Items 3, 16, $22,26,38,60$, and 62) yielded a Cronbach's alpha of .71. For the overall BKQ scale, which included all questionnaire items from Factors 1, 2, 3, 4, and 5 (a total of 40 items), the alpha value was .92 Therefore, the BKQ full scale and five subscales are considered reliable.

\section{Discriminant Function Analysis}

According to the results of the DFA, only one significant function was generated for the full scale, $\Lambda=.899, \chi^{2}(1)=28.08, p<.001$, indicating that the one-predictor function was able to differentiate between normal-weight and obese participants and to account for $10 \%$ of the variance. Likewise, for the five subscales, only one significant function was generated, $\Lambda=.683, \chi^{2}(5)=100.16, p<.001$, also 
indicating that the function containing the five predictors significantly differentiated between normal-weight and obese participants, accounting for $32 \%$ of the function variance for the fivepredictor model.

For the full BKQ scale, the classification results revealed that $92 \%$ of the normal-weight participants and $32 \%$ of the obese participants were classified correctly. Cross-validation derived $71 \%$ accuracy for the total sample. The means of the discriminant functions at the group centroids, 0.24 for normal weight and -0.46 for obese, suggest that individuals who score high on the full scale are likely to be classified as normal weight, whereas those who score low on the full scale are likely to be classified as obese.

For the five subscales, $90 \%$ of the normal-weight participants and $60 \%$ of the obese participants were classified correctly with cross-validation accuracy of $79 \%$ for the total sample. The means of the discriminant functions at the group centroids, 0.49 for normal weight and -0.94 for obese, suggest that individuals who score high on all five scales are likely to be classified as normal weight, whereas those who score low on the five scales are likely to be classified as obese.

From the DFAs, both the overall scale and subscales are significant predictors of normal weight and obese status. The five-subscale model was slightly better at predicting obese individuals with $79 \%$ accuracy compared with $71 \%$ accuracy for the full scale. Nevertheless, criterion-related (or predictive) validity for both the overall scale and subscales is established.

\section{Discussion}

Normally, to establish convergent validity, the correlations between two instruments are positive, but in the current research, the correlations between the BKQ and IWQOL-Lite are negative. This has occurred because higher scores on the IWQOL-Lite indicate poorer quality of life on, or a life more impeded by, the concept (i.e., obesity) measured by its scale or subscales, whereas higher scores on the BKQ indicate better weight management integration (i.e., normal weight). The expectation, therefore, is that poorer quality of life (or a high IWQOL-Lite score) would be correlated to lower weight management integration (or a low score on the BKQ), which is consistent with the negative correlations between the BKQ and IWQOL-Lite scale and subscales shown in Table 4.

In this study, a five-factor solution fit the data, whereas in the pilot study, a two-factor solution was appropriately identified. This difference is easily explained. The number of factors would be expected to increase when the number of items in the revised BKQ more than doubled. The results of this study suggest the newly added items widened the sampling of different aspects, or factors, across the weight management domain.

The statistical results of this study provide evidence of the validity of the BKQ, supporting a fivefactor solution. As well, there is evidence in the research literature for the existence of the five identified factors. In Allan's (1998) study, women reported that eating met their emotional needs, which provides support for the first factor, Emotional Eating. Additionally, Niemeier, Phelan, Fava, and Wing (2007) reported several emotions that contributed to weight gain. A study by Stuckey et al. (2011) provided support for the second factor, Health-Conscious Lifestyle. They found that those who exercised and enjoyed exercising managed to maintain a lower weight than those individuals who did not. Moreover, participants who ate the right foods like several portions of fresh fruits and vegetables daily rather than junk food had better weight control. 
The third factor, Conscientious Eating Habits, was found to be an important aspect in weight management in two studies. For example, Krassner, Brownell, and Stunkard (1979) reported that normal-weight individuals did not feel the need to eat all the food served on their plate (i.e., "clean their plate") at meal time. However, Rolls (2003) found that obese individuals do not adjust their consumption of food if they have eaten a snack just prior to a meal, and obese individuals will eat significantly more of an open package of prepackaged food than individuals who are not obese. Finally, in Hoke, Timmerman, and Robbins' (2006) exploratory descriptive study, they found that with some obese individuals, food was a central focus and seeing food prompted these individuals to eat. This supports the existence of Factor 4, Food Centricity.

The theory of integration (C. A. Hernandez, 1991, 1997) provides support for Factor 5, Psychosomatic Awareness. Normal-weight individuals maintain their normal-weight status because they are in tune (i.e., there is a psychosomatic awareness) with their body's needs, as suggested by the theory. Their thoughts are not centered on food (Factor 4, Food Centricity), and they are not prone to Emotional Eating (Factor 1). Normal-weight individuals live Health-Conscious Lifestyles (Factor 2) and have developed healthy, Conscientious Eating Habits (Factor 3). The individual's normal-weight self is the desired-weight self, and the attitudes, preferences, and behaviors of the individual support this ideal.

The results of this study provide evidence for the validity and reliability of the BKQ, which suggests that the BKQ is a viable instrument for identifying the attitudes, preferences, and behaviors central to weight management in adults. The BKQ can be used to differentiate between normal-weight and obese individuals with 79\% accuracy. Nonetheless, for two subscales-Conscientious Eating Habits and Food Centricity - the evidence of convergent validity was weak with only two of the six correlations providing support for convergent validity. Therefore, further psychometric testing of the BKQ with a larger sample is warranted, and the revised 40-item BKQ tool should be used in weight management research to develop and/or test the effectiveness of novel weight management interventions. Moreover, conducting a confirmatory factor analysis to provide greater confidence in the stability of psychometric results is important.

\section{Limitations}

A limitation of this research may be its relatively small sample size. Gorsuch (1983) and Kline (1994) recommended a minimum of 100 respondents for exploratory factor analysis. Furthermore, Guadagnoli and Velicer (1988) noted that 150 respondents were sufficient to obtain an accurate solution, and Cattell (1978) recommended a minimum sample size of 250 . Nevertheless, for good factor extraction, some researchers have recommended a minimum sample size of 300 participants (Comrey \& Lee, 1992; Tabachnick \& Fidell, 2012); though Gorsuch (1997) has suggested that prior estimates of sample size for EFA were well overstated. Nonetheless, in this study, 33 (12.4\%) more participants were needed to meet the 300-participant threshold. A second limitation is that the sampling strategy used for this research resulted in an underrepresentation of men (only 11.6\%) in the sample. Using a stratified sampling approach would have ensured equal numbers of male and female survey completers. 


\section{Implication for Practice and Research}

With continued psychometric testing, the BKQ instrument shows great potential for use in weight management practice areas such as diabetes education, dietetics, nursing, and psychology. Practitioners can use the instrument to assess an individual's attitudes, preferences, and behaviors related to weight management. Attitudes, preferences, and behaviors that are negative or problematic for an individual seeking to achieve or maintain a normal body weight can be identified, then strategies can be developed with the client to ameliorate one or more of these areas. Alternatively, the BKQ can be used to assess obese clients in a weight management clinic, and health professionals can focus discussion on individual questionnaire items in which a client's attitudes, preferences, and behaviors promote weight gain rather than weight loss. Additionally, the $\mathrm{BKQ}$ has potential for use in program evaluation if administered before and after education or intervention; for example, increased $\mathrm{BKQ}$ scores at the end of the diabetes education program would indicate positive learning outcomes. Finally, the BKQ could also be used as the basis for the development of tailored weight management interventions for individuals or groups.

This article described the development and testing of the BKQ, an instrument to measure the cognitive behavioral aspects of weight management integration. This research has shown that the $\mathrm{BKQ}$ instrument to be both valid and reliable. However, further testing with a larger sample is warranted.

\section{References}

Allan, J. D. (1998). Explanatory models of overweight among African American, Euro-American, and Mexican American women. Western Journal of Nursing Research, 20, 45-66. doi:10.1177/019394599802000104

Alpert, P. T. (2009). Obesity: A worldwide epidemic. Home Health Care Management \& Practice, 21, 442-444. doi:10.1177/1084822309334688

Bhupathiraju, S. N., \& Hu, F. B. (2016). Epidemiology of obesity and diabetes and their cardiovascular complications. Circulation Research, 118, 1723-1735. doi:10.1161/circresaha.115.306825

Breuhl Smith, K., \& Smith, M. S. (2016). Obesity statistics. Primary Care: Clinics in Office Practice, 43, 121-135. doi:10.1016/j.pop.2015.10.001

Butryn, M. L., Phelan, S., Hill, J. O., \& Wing, R. R. (2007). Consistent self-monitoring of weight: A key component of successful weight loss maintenance. Obesity, 15, 3091-3096. doi:10.1038/oby.2007.368

Cattell, R. B. (1966). The scree test for the number of factors. Multivariate Behavioral Research, 1, $245-276$.

Cattell, R. B. (1978). The scientific use of factor analysis in behavioral and life sciences. New York, NY: Plenum.

Compton, M. L. (2002). Women living with Crohn's disease (Unpublished master's thesis). University of Windsor, Ontario, Canada.

Comrey, A. L., \& Lee, H. B. (1992). A first course in factor analysis (2nd ed.). Hillsdale, NJ: Lawrence Erlbaum Associates. 
Deshaies, K., \& Hernandez, C. A. (2011). Integration: A phenomenon to explore in chronic nonmalignant pain (CNP). Pain Management Nursing, 12, 2-14. doi:10.1016/j.pmn.2009.10.004

DeVellis, R. F. (2017). Scale development: Theory and applications (4th ed., Vol. 26). Thousand Oaks, CA: Sage.

DiStefano, C., Zhu, M., \& Mîndrilă, D. (2009). Understanding and using factor scores: Considerations for the applied researcher. Practical Assessment, Research \& Evaluation, 14, 20. Retrieved from http://pareonline.net/pdf/v14n20.pdf

Drummond, R. J., Sheperis, C. J., \& Jones, K. D. (2016). Assessment procedures for counselors and helping professionals (8th ed.). Hoboken, NJ: Pearson.

Egger, G., \& Dixon, J. (2014). Beyond obesity and lifestyle: A review of 21st century chronic disease determinants. BioMed Research International, 2014, 731685. doi:10.1155/2014/731685

Field, A. (2013). Discovering statistics using SPSS (4th ed.). Thousand Oaks, CA: Sage.

Flegal, K. M., Kruszon-Moran, D., Carroll, M. D., Fryar, C. D., \& Ogden, C. L. (2016). Trends in obesity among adults in the United States, 2005 to 2014. Journal of the American Medical Association, 315, 2284-2291. doi:10.1001/jama.2016.6458

George, D., \& Mallery, P. (2016). IBM SPSS Statistics 23 step by step: A simple guide and reference (14th ed.). New York, NY: Routledge.

Gilmartin, J., \& Murphy, M. (2015). The effects of contemporary behavioural weight loss maintenance interventions for long term weight loss: A systematic review. Journal of Research in Nursing, 20, 481-496. doi:10.1177/1744987115599671

Gorsuch, R. L. (1983). Factor analysis (2nd ed.). Hillsdale, NJ: Lawrence Erlbaum Associates.

Gorsuch, R. L. (1997). Exploratory factor analysis: Its role in item analysis. Journal of Personality Assessment, 68, 532-560. doi:10.1207/s15327752jpa6803_5

Guadagnoli, E., \& Velicer, W. F. (1988). Relation of sample size to the stability of component patterns. Psychological Bulletin, 103, 265-275. doi:10.1037/0033-2909.103.2.265

Hernandez, C. A. (1991). The lived experience of type I diabetes: Implications for diabetes education. Dissertation Abstract International, A 53, 413.

Hernandez, C. A. (1997). Prediction of metabolic control in individuals with insulin-dependent diabetes mellitus. Dissertation Abstract International, B 58, 3556.

Hernandez, D. A., \& Hernandez, C. A. (2015). Weighing in on the Body Knowledge Questionnaire: Initial development and pilot testing. The Diabetes Educator, 40, 369-376. doi:10.1177/0145721715579107

Heron, M. (2013, December 20). Deaths: Leading causes for 2010. National Vital Statistics Reports, $62,1-96$.

Hoke, M. M., Timmerman, G. M., \& Robbins, L. K. (2006). Explanatory models of eating, weight, and health in rural Mexican American women. Hispanic Health Care International, 4, 143-151. doi:10.1891/hhci-v4i3a003

Johnson, R. (1990). Restructuring: An emerging theory on the process of losing weight. Journal of Advanced Nursing, 15, 1289-1296. doi:10.1111/1365-2648.ep8529668 
Kaiser, H. F. (1974). An index of factorial simplicity. Psychometrika, 39, 31-36. doi:10.1007/BF02291575

Kline, P. (1994). An easy guide to factor analysis. New York, NY: Routledge.

Kolotkin, R. L., Crosby, R. D., Kosloski, K. D., \& Williams, G. R. (2001). Development of a brief measure to assess quality of life in obesity. Obesity Research, 9, 102-111. doi:10.1038/oby.2001.13

Kraschnewski, J. L., Boan, J., Esposito, J., Sherwood, N. E., Lehman, E. B., Kephart, D. K., \& Sciamanna, C. N. (2010). Long-term weight loss maintenance in the United States. International Journal of Obesity, 34, 1644-1654. doi:10.1038/ijo.2010.94

Krassner, H. A., Brownell, K. D., \& Stunkard, A. J. (1979). Cleaning the plate: Food left over by overweight and normal weight persons. Behaviour Research and Therapy, 17, 155-156. doi:10.1016/0005-7967(79)90024-X

LoBiondo-Wood, G., \& Haber, J. (2014). Reliability and validity. In G. LoBiondo-Wood \& J. Haber (Eds.), Nursing research: Methods and critical appraisal for evidence-based practice (8th ed., pp. 289-309). St. Louis, MO: Mosby.

Mekary, R. A., Feskanich, D., Hu, F. B., Willett, W. C., \& Field, A. E. (2010). Physical activity in relation to long-term maintenance after intentional weight loss in premenopausal women. Obesity, 18, 167-174. doi:10.1038/oby.2009.170

Mertler, C. A., \& Vannatta, R. A. (2017). Advanced and multivariate statistical methods (6th ed.). New York, NY: Routledge.

Niemeier, H. M., Phelan, S., Fava, J. L., \& Wing, R. R. (2007). Internal disinhibition predicts weight regain following weight loss and weight loss maintenance. Obesity, 15, 2485-2494. doi:10.1038/oby.2007.295

Patrick, D. L., Burke, L. B., Gwaltney, C. J., Leidy, N. K., Martin, M. L., Molsen, E., \& Ring, L. (2011). Content validity-establishing and reporting the evidence in newly developed patient-reported outcomes (PRO) instruments for medical product evaluation: ISPOR PRO good research practices task force report: Part 2-assessing respondent understanding. Value in Health, 14, 978-988. doi:10.1016/j.jval.2011.06.013

Peirce, D., Brown, J., Corkish, V., Lane, M., \& Wilson, S. (2016). Instrument validation process: A case study using the paediatric pain knowledge and attitudes questionnaire. Journal of Clinical Nursing, 25, 1566-1575. doi:10.1111/jocn.13130

Rolls, B. J. (2003, March-April). The supersizing of America: Portion size and the obesity epidemic. Nutrition Today, 38, 42-53.

Stevens, J. P. (2009). Applied multivariate statistics for the social sciences (3rd ed.). New York, NY: Routledge.

Stuckey, H. L., Boan, J., Kraschnewski, J. L., Miller-Day, M., Lehman, E. B., \& Sciamanna, C. N. (2011). Using positive deviance for determining successful weight-control practices. Qualitative Health Research, 21, 563-579. doi:10.1177/1049732310386623

Sutton, D., \& Raines, D. A. (2010). Health-related quality of life following a surgical weight loss intervention. Applied Nursing Research, 23, 52-56. doi:10.1016/j.apnr.2008.01.001 
Swift, R. H., Harrigan, E. P., Cappelleri, J. C., Kramer, D., \& Chandler, L. P. (2002). Validation of the behavioural activity rating scale (BARS): A novel measure of activity in agitated patients. Journal of Psychiatric Research, 36, 87-95. doi:10.1016/S0022-3956(01)00052-8

Tabachnick, B. G., \& Fidell, L. S. (2012). Using multivariate statistics (6th ed.). Boston, MA: Pearson Education.

White, J. H. (1984). The process of embarking on a weight control program. Health Care for Women International, 5, 77-91. doi:10.1080/07399338409515639

Yong, A. G., \& Pearce, S. (2013). A beginner's guide to factor analysis: Focusing on exploratory factor analysis. Tutorials in Quantitative Methods for Psychology, 9, 79-94.

doi:10.20982/tqmp.09.2.p079

[Appendix follows] 


\section{Appendix}

\section{Content Validity Questionnaire}

The Body Knowledge Questionnaire (BKQ) is an instrument that measures a new concept called weight management integration. Weight management integration refers to the behaviors, attitudes, and preferences held (consciously or unconsciously) by individuals that help them maintain their current weight. The response format of the $\mathrm{BKQ}$ is a 6-point Likert scale from 1 (strongly disagree) to 6 (strongly agree), with most questions stated so that higher scores represent increased weight management integration (i.e., more likely to be reflective of normal weight). Some of the items are worded so that higher scores represent lower levels of weight management integration (i.e., are more reflective of obesity). These latter items will be reverse scored when the tool is actually being used, so you do not need to be concerned that the items are not all "going in the same direction."

Please answer the following questions based on your expertise (experiential and professional readings) in the area of weight management or bariatrics.

1. Are there any items that are missing (i.e., items representing other attitudes, preferences, and behaviors that you have found clearly distinguish between normal-weight and obese individuals)? If so, please list these below. Use the back of the page if necessary.

2. Are there any items that you think should not be included (i.e., items representing attitudes, preferences, and behaviors that you have not observed any difference between normal-weight and obese individuals)? If so, please write the item numbers below.

Item Number $\underline{\text { Explanation for Removal }}$

3. Are there any items that are difficult to understand either because (a) they are worded awkwardly or (b) they do not make sense given the Likert response format? If so, please list them below, and suggest alternative wording.

$\underline{\text { Item Number }}$
Better Wording 
4. Are there any words that would be difficult for your patients/clients to understand? If so, please list them below.

\author{
$\underline{\text { Item Number }} \quad$ Word(s) Difficult to Understand
}

5. Please time yourself, and take the questionnaire as if you were responding to it. How much time did it take? minutes

6. Optional: If you decide to allow the researchers to use the data from your responses to the $\mathrm{BKQ}$, please state your height and weight.
Height:
Weight:

The Journal of Social, Behavioral, and Health Sciences is an open-access, peer-reviewed, online interdisciplinary journal focusing on research findings that address contemporary national and international issues. Its objectives are to (a) encourage dialogue between scholars and practitioners in the social, behavioral, and health sciences that fosters the integration of research with practice; (b) promote innovative models of interdisciplinary collaboration among the social, behavioral, and health sciences that address complex social problems; and (c) inform the relationship between practice and research in the social, behavioral, and health sciences.

Walden University Publishing: http://www.publishing.waldenu.edu 